\title{
NK cells improve control of friend virus infection in mice persistently infected with murine cytomegalovirus
}

\author{
Sandra Francois ${ }^{1}$, Jing Peng ${ }^{1}$, Tatjana Schwarz ${ }^{1}$, Janine Duppach ${ }^{1}$, Kathrin Gibbert ${ }^{1}$, Ulf Dittmer $^{1}$ \\ and Anke RM Kraft ${ }^{1,2^{*}}$
}

\begin{abstract}
Background: Co-infection of HIV patients with cytomegalovirus (CMV) is associated with enhanced AIDS progression and CMV end-organ diseases. On the other hand, persistent CMV infection has recently been shown to decrease tumor relapse and protect against lethal bacterial infection. The influence of persistent CMV on the outcome of an acute retroviral superinfection is still unknown.

Results: Here we show that a persistent murine CMV (mCMV) infection surprisingly confers higher resistance to a primary Friend retrovirus infection (FV) of mice. Decreased FV titers and augmented FV-specific CD8 T-cell responses were found in mCMV infected mice during primary FV superinfection. NK cells produced higher amounts of IFNgamma after FV infection of persistently mCMV infected mice suggesting that these cells were involved in the 'protective' effect. Depletion of NK1.1 $1^{+}$cells or neutralization of IFNgamma during FV superinfection abrogated the mCMV-mediated effect.

Conclusion: Our data demonstrate for the first time that a persistent CMV infection induces long-lasting NK cell responses that can enhance immunity to primary retroviral infections. To our knowledge, studies investigating primary HIV infection have not analyzed the role of the CMV seropositivity in these patients. Our observations suggest that NK cells in CMV seropositive individuals might contribute to the control of primary HIV infection.
\end{abstract}

Keywords: Superinfection, Heterologous immunity, mCMV, Friend virus, NK cells, HIV, CMV

\section{Background}

Approximately 34 million people worldwide are currently infected with HIV and approximately 2.5 million new infections occur per year. Co-infections of HIV infected individuals with unrelated viruses like human cytomegalovirus (CMV) are associated with AIDS progression and CMV end-organ diseases (CMV-EOD) [1]. In a natural course of CMV/HIV co-infection, CMV-EOD occurs predominantly in HIV patients with low CD4 T cell counts [2-5]. CMV is a very common viral infection and approximately $40-80 \%$ of the human population worldwide is CMV seropositive. In an immunocompetent individual a primary CMV infection is mostly asymptomatic and during latency CMV is

\footnotetext{
* Correspondence: kraft.anke@mh-hannover.de

${ }^{1}$ Institute for Virology of the University Hospital in Essen, University of Duisburg-Essen, Essen, Germany

${ }^{2}$ Current address: Department of Gastroenterology, Hepatology and Endocrinology, Hannover Medical School, Hannover, Germany
}

well controlled by the immune system. CMV seropositivity in HIV infected patients or transplant recipients, as well as presence of CMV-infected cells in transplant organs, has been associated with poor prognosis, i.e. AIDS progression and transplant rejection [6-8]. However, these studies are mainly describing patients in the late phase of HIV infection when immunodeficiency starts to develop, but very little is known about acute HIV infection of CMV seropositive individuals. Recent publications have shown that persistent CMV infection can be beneficial for the host [9,10]; the group of Elmaagacli et al. showed that an early 'controlled' CMV replication reduced leukemia relapse in acute myeloid leukemia patients who underwent allogeneic stem cell transplantation [9]. Along with this finding, Barton et al. described that during persistent infection with murine cytomegalovirus (mCMV) or murine gammaherpesvirus 68 ( $\gamma \mathrm{HV} 68)$ mice are protected against lethal 
bacterial infections by prolonged macrophage activation and IFNY secretion [10]. To our knowledge nothing is known about the influence of a persistent CMV infection on a primary HIV infection. Based on the findings that CMV can be helpful for the host to control tumor relapse and bacterial superinfections it would be important to investigate the influence of a persistent $\mathrm{CMV}$ infection on the outcome of a primary retroviral infection.

Therefore, we established a mouse model to mimic a retroviral superinfection in a persistently CMV infected host. We used the well-established Friend virus (FV) as a model for retroviral infection and mCMV which has been used as a model to study CMV immunobiology and pathogenesis [11,12]. Similar to CMV, infectious mCMV can be isolated from infected mice over several months indicating a persistent infection. Additionally, strong NK cell and $\mathrm{T}$ cell responses are detectable in these mice [13]. Recently, it has been shown that NK cells are modulated during $\mathrm{mCMV}$ infection and memory-like NK cell population developed [14]. During acute mCMV infection the mCMV-specific protein $\mathrm{m} 157$ binds to the $\mathrm{Ly} 49 \mathrm{H}$ receptor of NK cells and induces a proliferation of this subpopulation $[15,16]$. Friend virus (FV) is a retroviral complex comprised of two components, the replication-competent non-pathogenic helper virus called Friend murine leukemia virus and the replication-defective pathogenic spleen focus-forming virus [17]. In adult C57BL/6 mice a primary FV infection induces a transient splenomegaly [18]. During the acute phase of infection, virus-specific CD8 $\mathrm{T}$ cells are important for controlling viral replication, but NK and CD4 T cells are not significantly contributing to keep the infection in check $[19,20]$.

Here we show for the first time that a persistent mCMV infection significantly reduced viral load during acute retroviral infection and demonstrate that mCMV induced NK cell and IFNY responses augmented antiviral $\mathrm{T}$ cell responses in vivo.

\section{Results}

Viral loads during primary FV infection were reduced in mice persistently infected with $\mathrm{mCMV}$

To study the influence of a persistent mCMV infection during primary $\mathrm{FV}$ infection, mice were infected i.p. with $\mathrm{mCMV}$. In the persistent phase of mCMV infection (510 weeks post infection), mice were superinfected i.v. with $\mathrm{FV}$. At this time point $\mathrm{mCMV}$ was detectable by plaque assay in livers and salivary glands (Additional file 1: Figure S1) indicating mice were in the persistent phase of mCMV infection. As a control, age-matched naïve mice were infected with FV only. At day 10 after FV infection the acute FV load was determined in spleens (Figure 1a). A significant 4-fold reduction of FV titers was detected in the superinfected mice compared to mice infected with FV alone (Figure 1a). This result suggests that a persistent mCMV infection might have a beneficial effect on the clearance and disease progression of a primary retroviral infection.

During the acute phase of FV infection, there is an increase in the number of erythrocyte precursor cells $\left(\right.$ Ter $\left.119^{+}\right)$, which represent the most important target cells of FV [21]. We therefore investigated if persistent mCMV infection interfered with the FV-induced expansion of Ter $119^{+}$target cells. However, we found no difference in number of Ter $119^{+}$cells in FV infected naïve and persistently mCMV infected mice (Figure $1 \mathrm{~b}$ ). Moreover, the numbers of $\mathrm{CD} 19^{+} \mathrm{B}$ cells, which also get infected by FV [21], were not different (Figure 1c). These data suggest that the reduced FV titers found in persistently mCMV infected mice were not a result of an impaired expansion of FV target cells.

\section{mCMV persistence augmented the FV-specific CD8 T cell response}

To determine if the reduced FV titers in persistently mCMV-infected mice were due to enhanced FV-specific immune responses, we analyzed the number of $\mathrm{FV}$ -
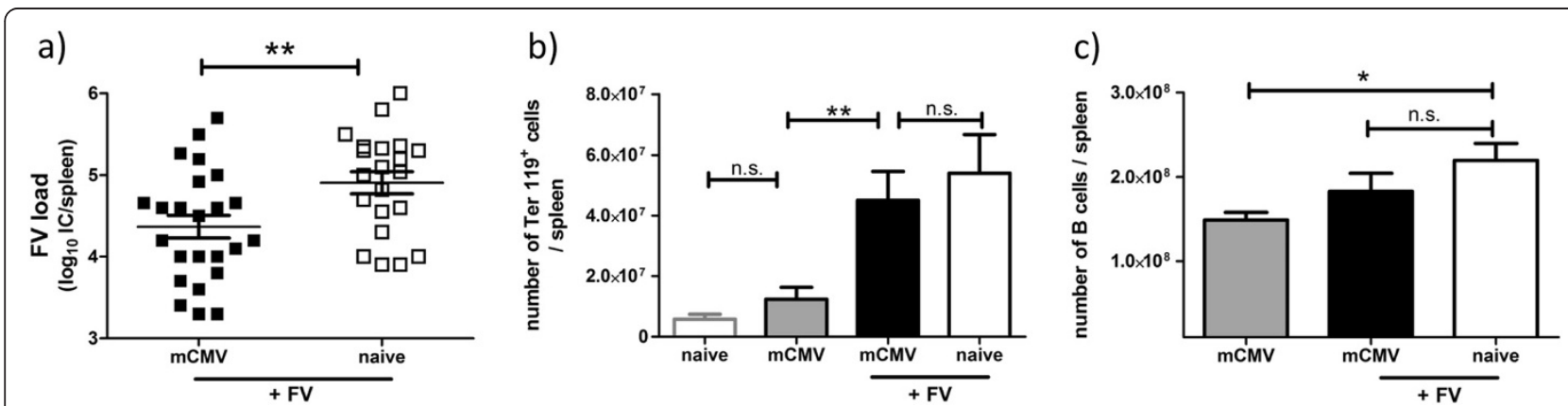

Figure $1 \mathrm{mCMV}$ persistence resulted in significantly decreased viral loads after FV superinfection. Naïve or persistently mCMV infected mice (day 35 post mCMV infection) were infected with FV. At day 10 post FV infection a) FV titers and $\mathbf{b}, \mathbf{c}$ ) FV-specific target cells (Ter119+ erythrocyte precursor cells, CD19+ B220 B cells) were determined in spleens. Statistical analysis a) unpaired student $t$-test, data pooled from 6 independent experiments, b) one-way ANOVA non-parametic Kruskal-Wallis test, data pooled from 3-4 independent experiments with 4-19 mice per group, c) one-way ANOVA Bonferroni's multiple comparison test, data pooled from 2 independent experiments with 9 mice per group. Statistically significant differences between the groups are indicated by n.s. no significant differences, ${ }^{*} p<0.05,{ }^{* *}$ for $p<0.001$. 
specific CD8 T cells by tetramer staining at day 8 and 10 post FV infection (Figure 2a). Significantly increased numbers of activated $\left(\mathrm{CD} 43^{+}\right) \mathrm{FV}$-specific CD8 T cells were found in FV superinfected compared to only FV infected mice (Figure 2a). These differences were determined at both 8 and 10 days post FV infection, indicating that the kinetic and the magnitude of the FV-specific CD8 T cell response might be influenced by persistent mCMV. In addition to an increased magnitude of FV-specific CD8 T cell responses in superinfected mice, these cells were functionally augmented by superinfection as well. First, a significant 3.5-fold increased number of granzyme $\mathrm{B}^{+} \mathrm{FV}$ specific $\mathrm{CD}^{+}{ }^{+}$tetramer ${ }^{+} \mathrm{T}$ cells was detected at day 8 p.i. in FV superinfected compared to only FV infected mice (Figure 2b). To confirm that the FV-specific CD8 T cells expressing granzyme B were cytotoxic in vivo, we performed an in vivo cytotoxicity assay. Splenocytes from a naive $C D 45.1^{+}$mouse were loaded with the same viral peptide recognized by the tetramer ${ }^{+} \mathrm{CD}^{+} \mathrm{T}$ cells and stained with CFSE. These labeled splenocytes together with unlabeled, control CD45.1 $1^{+}$splenocytes (without peptide) were injected i.v. into $\mathrm{CD} 45.2^{+}$naïve or persistently mCMV infected mice at day 8 after FV infection. In superinfected mice an average of $82 \%$ of the peptideloaded target cells were eliminated within 2 hours compared to a killing of $49 \%$ in only FV infected mice (Figure 2c). These data show that a persistent mCMV infection resulted in increased numbers of functional FV-specific CD8 T cells at day 8 of FV infection of persistently mCMV infected compared to naïve controls.

\section{NK cells and IFN $\gamma$ in persistently mCMV infected mice} contributed to enhanced FV-specific $\mathrm{T}$ cell responses During acute CMV infection, NK cells are activated, undergo clonal expansion, and generate long-lived memory cells [10,22]. Mice persistently infected with $\gamma \mathrm{HV} 68$ were protected against lethal challenge with Listeria monocytogenes due to enhanced IFN $\gamma$ levels in the sera and prolonged macrophage activation [10]. Similar protection against Listeria infection was found in mice persistently infected with mCMV [10]. In order to test whether IFN $\gamma$ and NK cell activity triggered by persistent mCMV infection contribute to enhanced FVspecific CD8 $\mathrm{T}$ cell responses, we first assessed IFN $\gamma$ levels in the sera of naïve compared to persistently mCMV infected mice. At the time of FV superinfections (around 35 days post mCMV infection) enhanced IFN $\gamma$ levels were detectable only in a few persistently mCMV infected mice and the overall difference between naïve and $\mathrm{mCMV}$ infected mice was not significant (data not shown). Similarly, one day and 4.5 days post FV superinfection only marginal concentrations of serum IFN $\gamma$ were found in persistently mCMV infected mice (data not shown). However, at 4.5 days post superinfection a greater proportion of NK cells from mCMV infected mice were producing intracellular IFN $\gamma$ relative to controls (Figure 3a,b). Notably, the Ly49 ${ }^{+} \mathrm{NK}$ cells, which have been shown to expand during mCMV infection due to interaction with the mCMV protein m157 [23], were the main producers of IFN $\gamma$ in superinfected mice (Figure 3b), whereas no significant difference in IFN $\gamma$ production was detectable in $\mathrm{Ly} 49 \mathrm{H}^{-} \mathrm{NK}$ cells from mice of the two groups (Figure 3c). There were no differences in the total number of NK cells present in naïve mice and mice persistently infected with $\mathrm{mCMV}$ (Figure 3d), but there were statistically significantly differences in the phenotype of splenic NK cells. Specifically, persistent mCMV infection was associated with increased numbers of CD62 $\mathrm{L}^{\text {low }}$ NK cells and elevated expression of KLRG-1 on NK cells (Figure 3e,f).

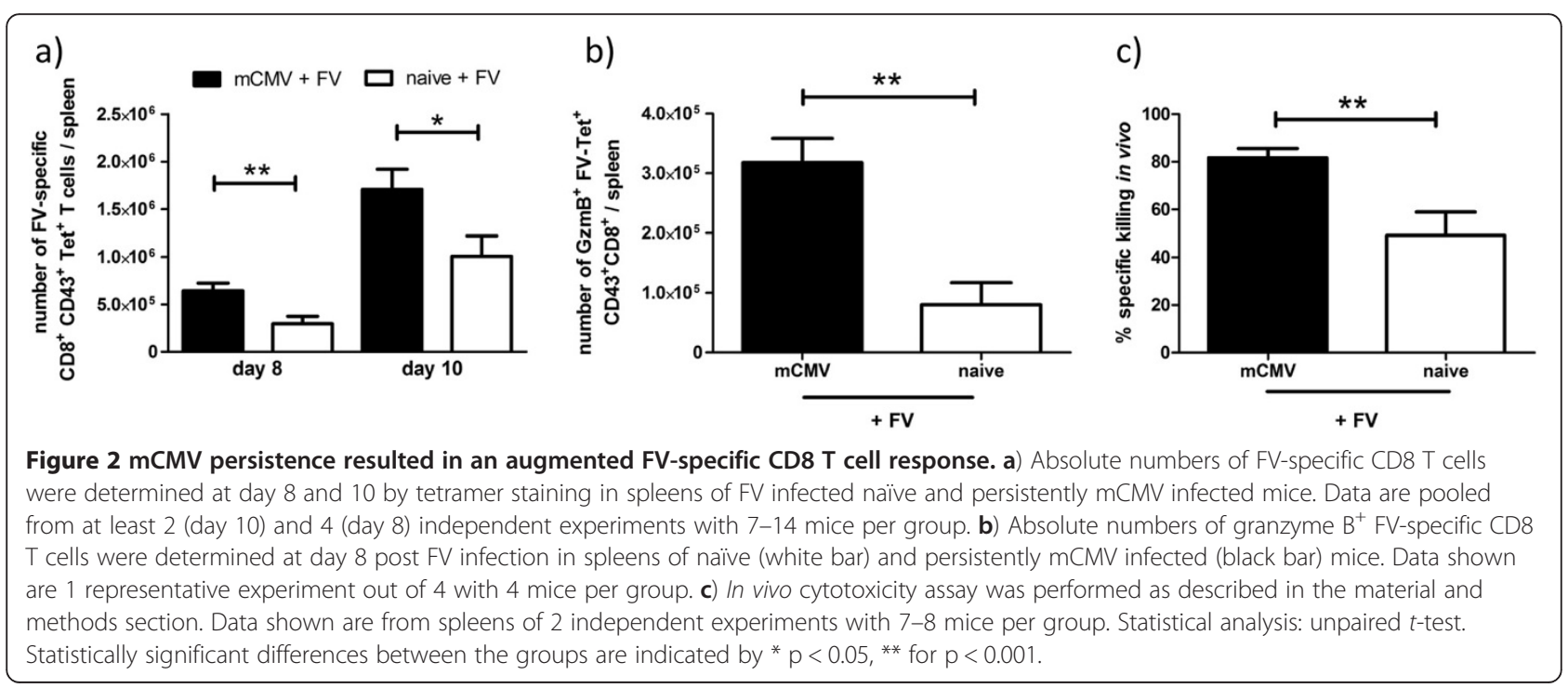




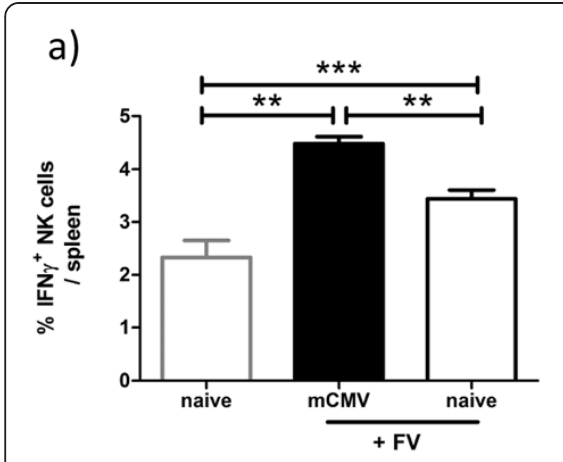

b)
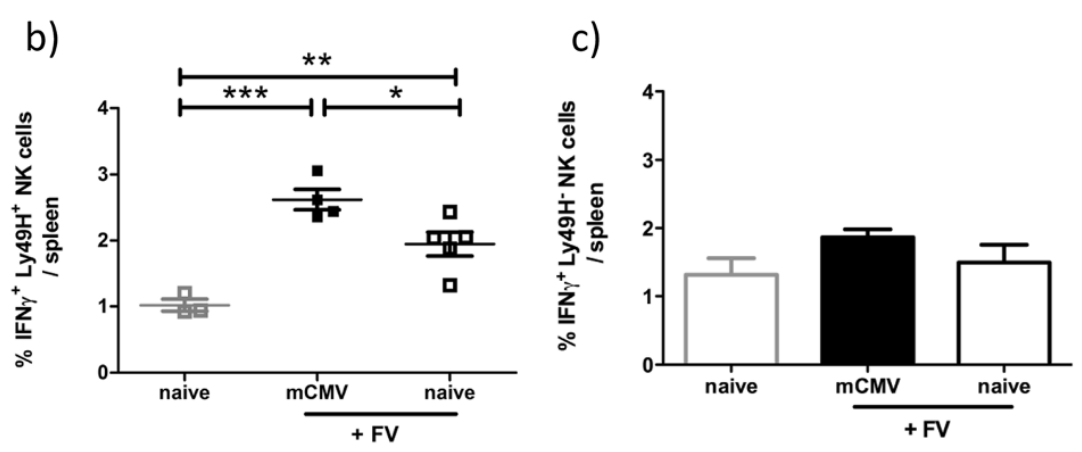

d)

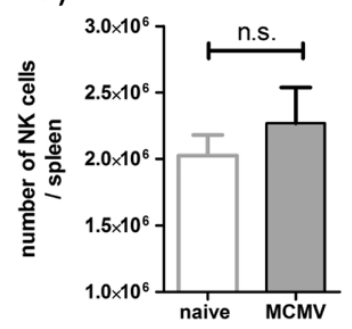

e)

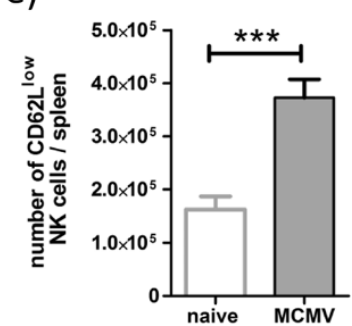

f)

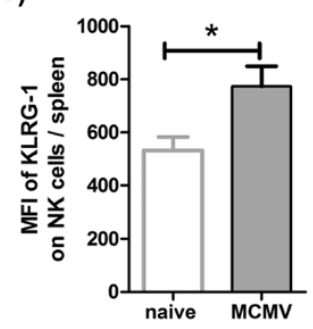

Figure 3 Enhanced numbers of NK cells were determined in persistently mCMV infected compared to naïve mice. IFNץ production by

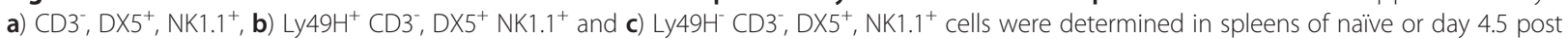
FV infection in naïve (white bar) and persistently mCMV (black bar) infected mice. $\mathbf{d}$-f ) NK cells were characterized in the spleen of naïve and persistently mCMV infected mice. d) Absolute numbers of NK cells were determined by gating of NK1. $1^{+} \mathrm{DX} 5^{+} \mathrm{CD} 3^{-}$cells. Absolute numbers of CD62L low $(\mathbf{e})$ and MFI of KLRG-1 (f) gated on NK1.1 ${ }^{+}$DX5 ${ }^{+}$CD3 $^{-}$cells were analyzed between the different groups. Data are pooled from d) 4-5 independent experiments with 9-16 mice per group, e,f) 3 independent experiments with 8-16 mice per group. Statistical analysis: unpaired $t$-test. Statistically significant differences between the groups are indicated by * $p<0.05,{ }^{* *}$ for $p<0.001, * * *$ for $p<0.0001$.

To further investigate whether the alterations in NK cell phenotype and function associated with persistent mCMV infection may contribute to the enhanced antiviral CD8 T cell responses observed during FV superinfection, NK1.1 $1^{+}$ cell depletions were performed prior to and during primary FV infection of persistently $\mathrm{mCMV}$ infected mice. In a separate experiment, we administered antibodies to block IFN $\gamma$ during FV superinfection in mCMV infected mice. Anti-IFNY or anti-NK1.1 antibodies were injected i.p. at day $-1,2$ and 4 of FV infection of naïve or persistently mCMV infected mice. At day 8 post FV infection, FV titers and FV-specific CD8 T cell responses were determined in spleens (Figure 4a, b). As seen previously, mice persistently infected with mCMV had significantly lower FV loads compared to mice infected with FV alone (Figure 4a, Figure 1a). Either depletion of NK1.1 ${ }^{+}$cells or blockade of IFN $\gamma$ during acute FV infection of persistently $\mathrm{mCMV}$ infected mice resulted in FV loads comparable to those in mice infected with FV alone, indicating that $\mathrm{NK} 1.1^{+}$cells and IFNy were involved in the mCMVinduced reduction of FV replication (Figure 4a). Since the FV-specific CD8 $\mathrm{T}$ cell response influences the FV load during acute infection, we quantified the FV-specific CD8 $\mathrm{T}$ cells after $\mathrm{NK} 1.1^{+}$cell depletion or IFN $\gamma$ blockade in persistently mCMV infected mice (Figure $4 b$ ). The significantly enhanced number of granzyme B producing FV- specific CD8 $\mathrm{T}$ cells detected in persistently mCMV infected mice after FV infection was completely abrogated if NK1.1 $1^{+}$cells (NK and NKT cells) were depleted or IFN $\gamma$ was blocked by antibodies. The number of $\mathrm{GzmB}^{+} \mathrm{FV}$ specific CD8 $\mathrm{T}$ cells in persistently $\mathrm{mCMV}$ infected mice receiving $\alpha-\mathrm{NK} 1.1$ or $\alpha$-IFN $\gamma$ antibodies were comparable to only FV infected mice (Figure $4 \mathrm{~b}$ ). As shown before, NK cells [19] and IFNY [24] have no direct effect on FV replication and FV-specific CD8 $\mathrm{T}$ cell responses between week one and two post FV infection of naïve mice (Additional file 2: Figure S2a-d).

\section{Discussion}

Our data demonstrate for the first time that a persistent mCMV infection can be beneficial during a primary retroviral infection by augmenting anti-retroviral CD8 T cell immunity that resulted in decreasing FV loads in superinfected mice.

Previous reports demonstrated that mice persistently infected with $\gamma \mathrm{HV} 68$ or mCMV were protected against superinfections with lethal doses of either Listeria monocytogenes or Yersinia pestis [10]. These effects were mediated by systemic activation of macrophages and prolonged IFN $\gamma$ production in $\gamma \mathrm{HV} 68$-infected mice. We were unable to detect prolonged macrophage activation $\left(\mathrm{F} 4 / 80^{+}, \mathrm{MHC}\right.$ classII $\left.{ }^{+}\right)$in the spleen or sustained IFN $\gamma$ 

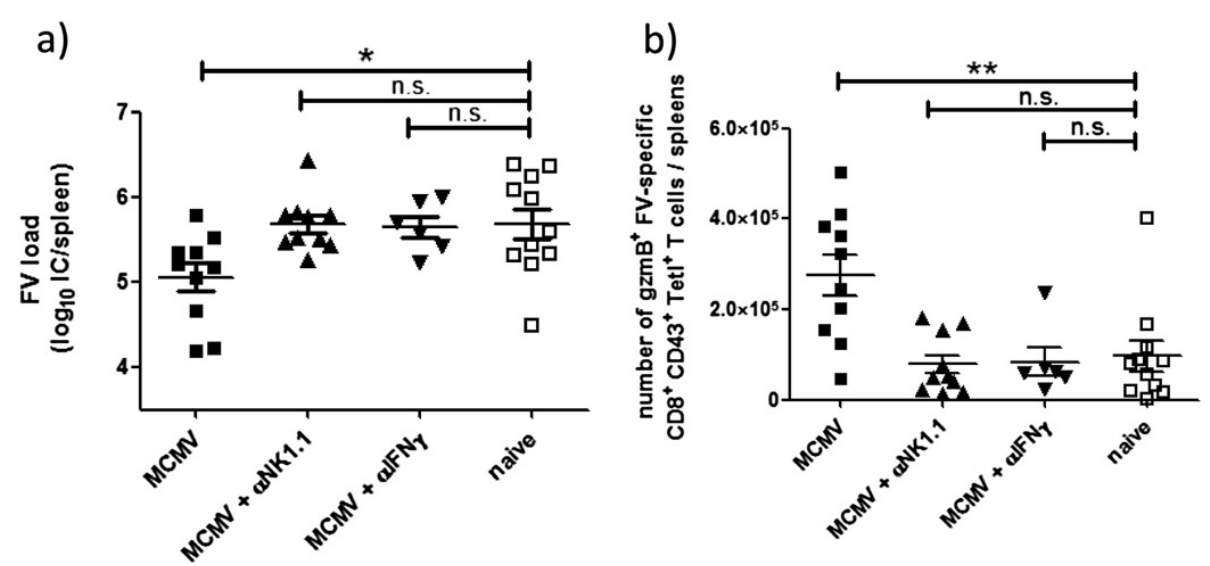

Figure 4 NK cells and IFNY in persistently mCMV infected mice contributed to reduced FV titers and enhanced FV-specific CD8 T cell responses. Depletion of $\mathrm{NK}_{1} \cdot 1^{+}$cells and blockage of IFNy was performed in persistently mCMV infected mice at day $-1,2$ and 4 post FV infections. As control naïve (white dots) and persistently mCMV infected (black dots) mice were superinfected with FV. FV loads were detected by an infectious center assay (a) and functional FV-specific CD8 T cells were determined by granzyme B expression gated on tetramer + CD8 T cells (b) at day 8 post FV infection. Data shown are pooled from 2-4 independent experiments. Statistical analysis: one-way ANOVA (Dunett's multiple comparison test). Statistically significant differences between the groups are indicated by n.s. no significant differences, ${ }^{*} p<0.05,{ }^{* *}$ for $p<0.001$.

secretion in the sera of mice persistently infected with mCMV (data not shown). A possible explanation is that a persistent $\gamma \mathrm{HV} 68$ infection triggers a higher expression of IFN $\gamma$ than the persistent $\mathrm{mCMV}$ infection. However, we were able to detect significant differences in the expression of IFNY in NK cells between naïve and persistently mCMV infected mice early after FV infection. Moreover, blocking IFN $\gamma$ during $\mathrm{FV}$ superinfection of mCMV infected mice resulted in enhanced FV titers and reduced $\mathrm{FV}$-specific CD8 $\mathrm{T}$ cell responses, indicating that IFNY was important in the mCMV-mediated effects. Depletion of NK1.1 $1^{+}$cells resulted in the same effect as IFN $\gamma$ blockage. Our NK1.1 $1^{+}$depletion protocol depleted NK cells as well as NKT cells, but no effect on $\gamma \delta^{+}$and $\alpha \beta^{+}$CD8 T cells was found (data not shown). Therefore the loss of NKT cells might also contribute to the effect described after NK1.1 ${ }^{+}$depletion. However, our data suggest that persistent $\mathrm{mCMV}$ infection mainly modulated the NK cell response that resulted in significantly enhanced numbers of IFN $\gamma^{+} \mathrm{NK}$ cells at day 4.5 post FV infection, which might positively influenced the FV-specific CD8 $\mathrm{T}$ cell response.

The influence of cytokines on CD8 T cell priming differs depending on the time-point and amount of cytokine secretion during T cell priming. For example IL-2 or type I IFN can enhance or inhibit $\mathrm{T}$ cell responses depending on the time-point after virus infection [25-28]. Virus-specific $\mathrm{CD} 8 \mathrm{~T}$ cell numbers are markedly reduced in $\mathrm{IFN}^{-/-}$and IFN $\gamma \mathrm{R}^{-1-}$ mice after LCMV infection [29] suggesting that IFN $\gamma$ can be necessary for an effective primary anti-viral CD8 $\mathrm{T}$ cell response. However, it has also been shown that IFNY can have a negative impact on virus-specific CD8 T cells [30]. In this study, a co-infection of FV together with the lactate dehydrogenase-elevating virus (LDV) resulted in a reduced FV-specific CD8 $\mathrm{T}$ cell response mediated by the strong LDV-dependent IFN $\gamma$ production. Duley et al. reported that high concentrations of serum IFN $\gamma$ were detected only immediately after infection ( 1 day post infection), which inhibited CD8 T cell priming. In contrast, high IFNy serum concentrations were not found in our study, but intracellular IFNy expression by splenic NK cells was detected starting at day 4.5 post FV infection of persistently $\mathrm{mCMV}$ infected mice. These results suggest that the timing and the strength of the IFN $\gamma$ response may be critical for its effect on CD8 T cell priming in FV infection. Our data is supported by a previous study showing that secretion of IFNY by activated NK cells can facilitate the priming of tumor-specific CD8 T cells [31].

Recent studies demonstrated that superinfections of $\beta$-herpesvirus infected mice with West Nile virus (WNV) or LCMV did not influence the outcome of the second infection $[10,32,33]$. There were no differences in the survival of naïve and $\gamma \mathrm{HV} 68$-infected mice after WNV superinfection [10]. Our current results may be different from these studies for a number of possible reasons: 1) NK cell activation likely differs during mCMV and $\gamma \mathrm{HV} 68$ infection 2) these activities of NK cells may be modulated by the virus dose or strain and 3) control of WNV might be mediated differently compared to FV since WNV replicates in neurons [34] whereas FV replicates in erythrocyte precursor cells and B cells. To our knowledge NK cell responses have not been characterized in persistently $\gamma \mathrm{HV} 68$ infected mice so far.

Recently Mekker et al. published that LCMV clearance in mice was not influenced by persistent $\mathrm{mCMV}$ infection [32]. In their mCMV infection model the virus was 
cleared at 6-8 weeks post infection whereas we could detect replicating $\mathrm{mCMV}$ in salivary glands at least up to 12 weeks post mCMV infection (Additional file 1: Figure S1) suggesting that replicating mCMV might be necessary to influence anti-viral immune responses against a secondary infection. Additionally Mekker et al. used the mCMV $\triangle \mathrm{m} 157$ virus, which does not induce a strong NK cell response in C57BL/6 mice. Instead, we used the mCMV Smith strain in C57BL/6 mice, which was shown to induce strong NK cell response that is responsible for the early control of the mCMV infection [23]. The mCMV specific m157 protein binds to the NK cell receptor Ly49H and induces strong NK cell activation and proliferation. This interaction combined with long-term virus replication might be necessary to generate effector and/or memory NK cell responses, which can improve anti-viral immune responses [35].

Our data suggests that mCMV-primed NK cells increased the magnitude of the FV-specific CD8 T cell response. At first glance our findings seem to be contradictory to recently published studies showing a negative effect of NK cells on the priming of virus-specific CD8 $T$ cell responses [36-38]. However, in these studies the impact of NK cells on the outcome of a primary virus infection was examined in previously naïve mice. In our study, we demonstrated the positive impact of previously activated, memory-type NK cells in mice persistently infected with mCMV on the priming of retrovirus-specific CD8 T cells. In high-risk HIV-exposed seronegative individuals, an increased NK cell activity has been found, indicating that NK cells might also be involved in the resistance against primary HIV-1 infection $[39,40]$.

Our current data also seem to contradict previous studies on the interaction of CMV and retroviruses in HIV infected patients. These studies demonstrate reactivation of CMV in the late stage of HIV infection, when patients have low CD4 $\mathrm{T}$ cell counts [2-5] and a drop in CMVspecific CD4 $\mathrm{T}$ cell numbers [6]. Under these circumstances CMV seropositivity can clearly be harmful for a retrovirus infected host. However, here we studied a primary retrovirus infection in a CMV seropositive host, a scenario that has not been studied so far in HIV infected patients. These contradictory findings indicate that on one hand CMV seropositivity might be beneficial during a primary retrovirus infection on the other hand it becomes detrimental during a chronic retrovirus infection.

\section{Conclusion}

Taken together, mCMV primed NK cells that produce IFN $\gamma$ were able to promote the FV-specific CD8 T cell response after FV superinfection. Our results suggest that activated NK cells in CMV seropositive individuals might also contribute to the control of primary HIV infection.
There are several studies on primary HIV infection but none of them analyzes the CMV status of these patients.

\section{Methods \\ Mice}

Six to eight weeks old C57BL/6 (H-2b) male mice were obtained from Harlan (Horst, Netherlands). The mice were infected i.p. with $1 \times 10^{5}$ PFU mCMV (Smith strain) or were inoculated with PBS as control. The mCMV stock was prepared from salivary glands of Balb/ c mice 15 days post infection [41]. During the persistent phase (5-10 weeks post infection), persistently mCMV and naive mice (controls) were infected i.v. with 20,000 spleen focus-forming units (SFFU) of Friend virus (FV). The FV stock was obtained from 15\% spleen cell homogenates from $\mathrm{BALB} / \mathrm{c}$ mice infected 14 days previously with 3,000 SFFU. The FV stock was not contaminated by lactate dehydrogenase-elevating virus (LDV) [42]. All virus stocks were diluted with PBS. Mice were maintained under pathogen-free conditions and treated in according with the regulations and guidelines of institutional animal care of the University Duisburg-Essen, Germany.

\section{Virus titer detection}

Titrations of single-cell suspensions of FV infected splenocytes were performed on susceptible Mus dunni cells, co-cultivated for 3 days and stained with F-MuLV envelope-specific monoclonal antibody 720 as previously described [43]. Results were detected as $\log _{10}$ infectious centers (IC) per spleen.

The number of $\mathrm{mCMV}$ PFU was determined by plaque assay using a $10 \%$ homogenate of tissue taken from individual mice and tenfold dilutions of this homogenate on mouse embryonic fibroblasts (GTKO) cells were used to quantify mCMV titers [44]. Titers reported are numbers of $\log _{10}$ PFU per whole liver and salivary gland.

\section{Cell-surface and intracellular staining by flow cytometry}

Cell-surface staining was performed with the following antibodies: anti-CD3 (17A2), anti-CD49b (DX5), anti-CD69 (H1.2 F3), anti-NK1.1 (PK136), anti-CD43 (1B11), anti-CD4 (RM4-5), anti-CD8 (53-6.7), anti-CD107a (1D4B), antiTer119 (TER-119), anti-KLRG-1 (2 F1), anti-CD44 (IM7), anti-CD19 (MB19-1), anti-B220 (RA3-6B2) and antiCD62L (MEL-14).

Dead cells (positive for fixable viable dye; eBioscience) were excluded from analysis. Data were acquired on a LSR II flow cytometer (BD Biosciences) and analyses were performed using FACSDiva (BD Biosciences) and Flow Jo (Tree Star) software.

For intracellular staining of IFN $\gamma$ in NK cells, up to $4 \times$ $10^{6}$ splenocytes were stimulated with PMA (400 ng/ml) and ionomycin $(500 \mathrm{ng} / \mathrm{ml})$ in the presence of brefeldin A for $3 \mathrm{~h}$ at $37^{\circ} \mathrm{C}$. Stimulated cells were pre-incubated with 
an Fc Block (2.4G2) in FACS buffer (HBBS, 2\% FCS, 0.1\% $\mathrm{NaN}_{3}$ ) and stained for $20 \mathrm{~min}$ at $4{ }^{\circ} \mathrm{C}$ with various combinations of fluorescently tagged monoclonal antibodies. After washing, cells were permeabilized using BD Cytofix/ Cytoperm solution and then stained in BD Permwash using monoclonal antibodies specific for various cytokines. Intracellular staining of granzmye B (clone GB12) and Foxp3 was performed without in vitro stimulation. Foxp3 expression was detected using the Foxp3 antibody (clone FJK-16 s) and the Foxp3 staining kit (eBioscience).

\section{Tetramers and tetramer staining}

For quantification of virus-specific CD8 $\mathrm{T}$ cells, spleen cells were stained with anti-CD8, anti-CD43 and MHC class I H2-D ${ }^{\mathrm{b}}$ tetramers specific for the FV GagL epitope $[45,46]$ for $30 \mathrm{~min}$ at room temperature as described [47].

\section{In vivo cytotoxicity assay}

The in vivo CTL assay was performed as described previously [47]. Briefly, splenocytes from naive CD $45.1^{+} \mathrm{C} 57 \mathrm{BL} /$ 6 mice were loaded with $1 \mu \mathrm{M} \mathrm{D}{ }^{\mathrm{b}} \mathrm{GagL}$ peptide $[45,46]$. These loaded splenocytes were stained with $200 \mathrm{nM}$ 5(and 6-) carboxyfluorescein diacetate succinimidyl ester (CFSE; Molecular Probes). As control, spleen cells without peptide and no CSFE labeling were used. Peptide loaded and non-loaded splenocytes were mixed 1:1 and transferred i.v. ( $10^{7}$ cells of each population) into FV-infected CD $45.2^{+}$C56BL/6 mice at day 8 post FV infection. Two hours after the transfer of cells, splenocytes were harvested, and cell suspensions were prepared. Target cells were distinguished from recipient cells by the surface molecules CD45.1 and CD45.1 and peptide loaded and non-loaded cells by CFSE staining. The percentage of killing was calculated as follows: 100 - ([(\% peptide pulsed in infected/\% unpulsed in infected $) /(\%$ peptide pulsed in uninfected/\% unpulsed in uninfected)] $\times 100$ ).

\section{Antibody treatment}

NK $1.1^{+}$cell depletion was performed using $0.5 \mathrm{ml}$ of supernatant fluid containing NK1.1-specific monoclonal antibody PK136 [48]. Four days after the last NK1.1 injection over $90 \%$ off all NK cells $\left(\mathrm{DX} 5^{+}, \mathrm{NK} 1.1^{+}, \mathrm{NKp} 46^{+}\right.$, $\mathrm{CD}^{-}$) were depleted in naïve and persistently mCMV infected mice. Additionally we detected an up to $89 \%$ depletion of NKT cells $\left(\mathrm{NK} 1.1^{+}, \mathrm{NKp} 46^{+}, \mathrm{CD}^{-}\right)$in naïve and persistently mCMV infected mice at this time-point. No depletion of $\gamma \delta \mathrm{T}$ and CD8 T cells was detected after NK1.1 antibody injection. Neutralization of IFNY was done by injection of 150 to $250 \mu \mathrm{g}$ XMG1.2 antibody in $0.2 \mathrm{ml}$ PBS (Bio-X-Cell). Antibodies were injected i.p. into mice at day $-1,2$ and 4 post $\mathrm{FV}$ infection.

\section{Cytokine assay}

Mouse IFN $\gamma$ levels were detected using the Femto-HS Elisa kit (eBioscience) according to the manufacturers' instructions.

\section{Ethics statement}

Animal experiments were performed in strict accordance with the German regulations of the Society for Laboratory Animal Science (GV-SOLAS) and the European Health Law of the Federation of Laboratory Animal Science Associations (FELASA). The protocol was approved by the North Rhine-Westphalia State Agency for Nature, Environment and Consumer Protection (LANUF). All efforts were made to minimize suffering.

\section{Additional files}

Additional file 1: Figure S1. Replication of persistent mCMV. MCMV loads were analyzed at 5-10 weeks post mCMV infection in livers and salivary glands. Data are pooled from 4 independent experiments with 16-19 mice per group

Additional file 2: Figure S2. NK cell depletion or IFNy neutralization had no direct effect on viral loads or T cell responses in FV infection. Naiive mice were infected with $\mathrm{FV}$ and $\mathrm{a}, \mathrm{c}$ ) viral loads and b,d) granzyme ${ }^{+}$ $\mathrm{FV}$ tetramer ${ }^{+} \mathrm{T}$ cells were determined in untreated (open circles, white bars) and anti-NK1.1 or anti-IFNy antibody (half-filled circles, stripped bars) treated mice at day 8 post $F V$ infection. Data represent the mean of two individual experiments with 4-7 mice/group.

\section{Competing interests}

The authors declare that they have no competing interests.

\section{Authors' contributions}

SF, JP, TS, JD carried out experiments and analyzed the data; KG, UD analyzed data; ARMK and UD wrote the manuscript. All authors read and approved the final manuscript.

\section{Acknowledgements}

We thank Stephen Waggoner (University of Massachusetts Medical School) for advise and critical reading the manuscript. This work was supported by a grant from the Deutsche Forschungsgemeinschaft (TRR60) and from the University Hospital Essen (IFORES).

Received: 2 January 2013 Accepted: 19 May 2013

Published: 5 June 2013

\section{References}

1. Mori Y, Yamanishi K: HHV-6A, 6B, and 7: pathogenesis, host response, and clinical disease. In Human Herpesviruses: Biology, Therapy, and Immunoprophylaxis. Edited by Arvin A, Campadelli-Fiume G, Mocarski E, Moore PS, Roizman B, Whitley R, Yamanishi K. Cambridge: Cambridge University Press; 2007. Chapter 46.

2. Bronke C, Palmer NM, Jansen CA, Westerlaken GH, Polstra AM, Reiss P, Bakker M, Miedema F, Tesselaar K, van Baarle D: Dynamics of cytomegalovirus (CMV)-specific T cells in HIV-1-infected individuals progressing to AIDS with CMV end-organ disease. J Infect Dis 2005, 191:873-880.

3. Bronke C, Westerlaken GH, Miedema F, Tesselaar K, van Baarle D: Progression to CMV end-organ disease in HIV-1-infected individuals despite abundance of highly differentiated CMV-specific CD8+ T-cells. Immunol Lett 2005, 97:215-224

4. Sison RF, Holland GN, MacArthur LJ, Wheeler NC, Gottlieb MS: Cytomegalovirus retinopathy as the initial manifestation of the acquired immunodeficiency syndrome. Am J Ophthalmol 1991, 112:243-249. 
5. Erice A, Tierney C, Hirsch M, Caliendo AM, Weinberg A, Kendall MA, Polsky B: Cytomegalovirus (CMV) and human immunodeficiency virus (HIV) burden, CMV end-organ disease, and survival in subjects with advanced HIV infection (AIDS clinical trials group protocol 360). Clin Infect Dis 2003, 37:567-578.

6. Guardia-Silva AC, Stucchi RS, Sampaio AM, Milan A, Costa SC, Boin IF: Detection of cytomegalovirus and human herpesvirus-6 DNA in liver biopsy specimens and their correlation with rejection after liver transplantation. Transplant Proc 2012, 44:2441-2444.

7. van der Bij W, Speich R: Management of cytomegalovirus infection and disease after solid-organ transplantation. Clin Infect Dis 2001, 33(Suppl 1):S32-S37.

8. Lerner CW, Tapper ML: Opportunistic infection complicating acquired immune deficiency syndrome. Clinical features of 25 cases. Medicine (Baltimore) 1984, 63:155-164

9. Elmaagacli $\mathrm{AH}$, Steckel NK, Koldehoff M, Hegerfeldt $Y$, Trenschel R, Ditschkowski M, Christoph S, Gromke T, Kordelas L, Ottinger HD, et al: Early human cytomegalovirus replication after transplantation is associated with a decreased relapse risk: evidence for a putative virus-versus-leukemia effect in acute myeloid leukemia patients. Blood 2011, 118:1402-1412.

10. Barton ES, White DW, Cathelyn JS, Brett-McClellan KA, Engle M, Diamond MS, Miller VL, Virgin HWT: Herpesvirus latency confers symbiotic protection from bacterial infection. Nature 2007, 447:326-329.

11. Krmpotic A, Bubic I, Polic B, Lucin P, Jonjic S: Pathogenesis of murine cytomegalovirus infection. Microbes Infect 2003, 5:1263-1277.

12. Reddehase MJ, Simon CO, Seckert CK, Lemmermann N, Grzimek NK: Murine model of cytomegalovirus latency and reactivation. Curr Top Microbiol Immunol 2008, 325:315-331.

13. Lopez-Verges S, Milush JM, Schwartz BS, Pando MJ, Jarjoura J, York VA, Houchins JP, Miller S, Kang SM, Norris PJ, et al: Expansion of a unique CD57(+)NKG2Chi natural killer cell subset during acute human cytomegalovirus infection. Proc Natl Acad Sci U S A 2011, 108:14725-14732.

14. Sun JC, Lopez-Verges S, Kim CC, DeRisi JL, Lanier LL: NK cells and immune "memory". J Immunol 2011, 186:1891-1897.

15. Arase H, Mocarski ES, Campbell AE, Hill AB, Lanier LL: Direct recognition of cytomegalovirus by activating and inhibitory NK cell receptors. science 2002, 296:1323-1326.

16. Smith HR, Heusel JW, Mehta IK, Kim S, Dorner BG, Naidenko OV, lizuka K, Furukawa H, Beckman DL, Pingel JT, et al: Recognition of a virus-encoded ligand by a natural killer cell activation receptor. Proc Natl Acad Sci USA 2002, 99:8826-8831.

17. Kabat D: Molecular biology of friend viral erythroleukemia. Curr Top Microbiol Immunol 1989, 148:1-42.

18. Chesebro B, Wehrly K, Stimpfling J: Host genetic control of recovery from friend leukemia virus-induced splenomegaly: mapping of a gene within the major histocompatability complex. J Exp Med 1974, 140:1457-1467.

19. Zelinskyy G, Balkow S, Schimmer S, Werner T, Simon MM, Dittmer U: The level of friend retrovirus replication determines the cytolytic pathway of CD8+ T-cell-mediated pathogen control. J Virol 2007, 81:11881-11890.

20. Gerlach N, Schimmer S, Weiss S, Kalinke U, Dittmer U: Effects of type I interferons on friend retrovirus infection. J Virol 2006, 80:3438-3444.

21. Hasenkrug KJ, Brooks DM, Dittmer U: Critical role for CD4(+) T cells in controlling retrovirus replication and spread in persistently infected mice. J Virol 1998, 72:6559-6564.

22. Sun JC, Lanier LL: NK cell development, homeostasis and function: parallels with CD8(+) T cells. Nat Rev Immunol 2011, 11:645-657.

23. Dokun AO, Kim S, Smith HR, Kang HS, Chu DT, Yokoyama WM: Specific and nonspecific NK cell activation during virus infection. Nat Immunol 2001, 2:951-956

24. Stromnes IM, Dittmer U, Schumacher TN, Schepers K, Messer RJ, Evans LH, Peterson KE, Race B, Hasenkrug KJ: Temporal effects of gamma interferon deficiency on the course of friend retrovirus infection in mice. J Virol 2002, 76:2225-2232.

25. Blattman JN, Grayson JM, Wherry EJ, Kaech SM, Smith KA, Ahmed R: Therapeutic use of IL-2 to enhance antiviral T-cell responses in vivo. Nat Med 2003, 9:540-547.

26. Van Parijs L, Refaeli Y, Lord JD, Nelson BH, Abbas AK, Baltimore D: Uncoupling IL-2 signals that regulate T cell proliferation, survival, and Fas-mediated activation-induced cell death. Immunity 1999, 11:281-288.

27. Tough DF, Borrow P, Sprent J: Induction of bystander T cell proliferation by viruses and type I interferon in vivo. Science 1996, 272:1947-1950.

28. McNally JM, Zarozinski CC, Lin MY, Brehm MA, Chen HD, Welsh RM: Attrition of bystander CD8 T cells during virus-induced T-cell and interferon responses. J Virol 2001, 75:5965-5976.
29. Whitmire JK, Tan JT, Whitton JL: Interferon-gamma acts directly on CD8+ T cells to increase their abundance during virus infection. J Exp Med 2005, 201:1053-1059.

30. Duley AK, Ploquin MJ, Eksmond U, Ammann CG, Messer RJ, Myers L, Hasenkrug KJ, Kassiotis G: Negative impact of IFN-gamma on early host immune responses to retroviral infection. J Immunol 2012, 189:2521-2529.

31. Fan Z, Yu P, Wang Y, Fu ML, Liu W, Sun Y, Fu YX: NK-cell activation by LIGHT triggers tumor-specific CD8+ T-cell immunity to reject established tumors. Blood 2006, 107:1342-1351.

32. Mekker A, Tchang VS, Haeberli L, Oxenius A, Trkola A, Karrer U: Immune senescence: relative contributions of age and cytomegalovirus infection. PLOS Pathog 2012, 8:e1002850.

33. Cicin-Sain L, Brien JD, Uhrlaub JL, Drabig A, Marandu TF, Nikolich-Zugich J: Cytomegalovirus infection impairs immune responses and accentuates T-cell pool changes observed in mice with aging. PLOS Pathog 2012, 8:e1002849.

34. Shrestha B, Gottlieb D, Diamond MS: Infection and injury of neurons by west nile encephalitis virus. J Virol 2003, 77:13203-13213.

35. Babic M, Krmpotic A, Jonjic S: All is fair in virus-host interactions: NK cells and cytomegalovirus. Trends Mol Med 2011, 17:677-685.

36. Mitrovic M, Arapovic J, Jordan S, Fodil-Cornu N, Ebert S, Vidal SM, Krmpotic A, Reddehase MJ, Jonjic S: The NK cell response to mouse cytomegalovirus infection affects the level and kinetics of the early CD8(+) T-cell response. J Virol 2012, 86:2165-2175

37. Waggoner SN, Cornberg M, Selin LK, Welsh RM: Natural killer cells act as rheostats modulating antiviral T cells. Nature 2011, 481:394-398.

38. Lang PA, Lang KS, Xu HC, Grusdat M, Parish IA, Recher M, Elford AR, Dhanji S, Shaabani N, Tran CW, et al: Natural killer cell activation enhances immune pathology and promotes chronic infection by limiting CD8+ T-cell immunity. Proc Natl Acad Sci U S A 2012, 109:1210-1215.

39. Ravet S, Scott-Algara D, Bonnet E, Tran HK, Tran T, Nguyen N, Truong LX, Theodorou I, Barre-Sinoussi F, Pancino G, Paul P: Distinctive NK-cell receptor repertoires sustain high-level constitutive NK-cell activation in HIV-exposed uninfected individuals. Blood 2007, 109:4296-4305.

40. Scott-Algara D, Truong LX, Versmisse P, David A, Luong TT, Nguyen NV, Theodorou I, Barre-Sinoussi F, Pancino G: Cutting edge: increased NK cell activity in HIV-1-exposed but uninfected Vietnamese intravascular drug users. J Immunol 2003, 171:5663-5667.

41. Bukowski JF, Woda BA, Habu S, Okumura K, Welsh RM: Natural killer cell depletion enhances virus synthesis and virus-induced hepatitis in vivo. J Immunol 1983, 131:1531-1538.

42. Robertson SJ, Ammann CG, Messer RJ, Carmody AB, Myers L, Dittmer U, Nair S, Gerlach N, Evans LH, Cafruny WA, Hasenkrug KJ: Suppression of acute anti-friend virus CD8+ T-cell responses by coinfection with lactate dehydrogenase-elevating virus. J Virol 2008, 82:408-418.

43. Dittmer U, Brooks DM, Hasenkrug KJ: Characterization of a live-attenuated retroviral vaccine demonstrates protection via immune mechanisms. J Virol 1998, 72:6554-6558.

44. Chen HD, Fraire AE, Joris I, Welsh RM, Selin LK: Specific history of heterologous virus infections determines anti-viral immunity and immunopathology in the lung. Am J Pathol 2003, 163:1341-1355.

45. Chen W, Qin H, Chesebro B, Cheever MA: Identification of a gag-encoded cytotoxic T-lymphocyte epitope from FBL-3 leukemia shared by friend, moloney, and rauscher murine leukemia virus-induced tumors. J Virol 1996, 70:7773-7782.

46. Schepers K, Toebes M, Sotthewes G, Vyth-Dreese FA, Dellemijn TA, Melief CJ, Ossendorp F, Schumacher TN: Differential kinetics of antigen-specific $\mathrm{CD} 4+$ and $\mathrm{CD} 8+\mathrm{T}$ cell responses in the regression of retrovirus-induced sarcomas. J Immunol 2002, 169:3191-3199.

47. Zelinskyy G, Dietze KK, Husecken YP, Schimmer S, Nair S, Werner T, Gibbert K, Kershaw O, Gruber AD, Sparwasser T, Dittmer U: The regulatory T-cell response during acute retroviral infection is locally defined and controls the magnitude and duration of the virus-specific cytotoxic T-cell response. Blood 2009, 114:3199-3207.

48. Gibbert K, Joedicke JJ, Meryk A, Trilling M, Francois S, Duppach J, Kraft A Lang KS, Dittmer U: Interferon-alpha subtype 11 activates NK cells and enables control of retroviral infection. PLOS Pathog 2012, 8:e1002868.

doi:10.1186/1742-4690-10-58

Cite this article as: Francois et al: NK cells improve control of friend virus infection in mice persistently infected with murine cytomegalovirus. Retrovirology 2013 10:58. 